https://doi.org/10.31852/EMF.31.2019.023.031

\title{
THE INFLUENCE OF URBAN SCALE SPATIAL MORPHOLOGY ON THERMAL ENVIRONMENT IN ZHENGZHOU, CHINA - A CASE STUDY
}

\author{
Guo Yuchen \\ University of Szeged, Department of Climatology and Landscape Ecology \\ Szeged, Egyetem u. 2. \\ e-mail: yuchenguo@geo.u-szeged.hu
}

\section{Introduction}

In recent years, due to the fast urbanization, the urban spatial morphology has changed a lot in many cities of China, which results in a great impact on the urban climate. The urban thermal environment in Zhengzhou City, which is a fast-growing provincial capital city, has also deteriorated in recent years with the urbanization process and global warming. Since 1992, urban temperature has increased significantly, and there is a significant positive correlation between urban heat island intensity and urban construction indicators in Zhengzhou (Zhang et al., 2016).

According to the traditional definition, the urban heat island intensity refers to the difference between urban and rural temperatures. However, the definition between urban and rural is very general. Usually, cities or villages still contain many different kinds of surface coverage. For example, urban areas include architectural areas, roads, urban parks, etc. And rural areas include farmland, settlement, forests, etc. The temperature in urban or rural areas may be different in different studies. It makes difficult to compare the results obtained in the different studies of the world (Stewart, 2011).

In order to solve this problem, Stewart \& Oke (2012) developed a classification, the local climate zone (LCZ) system, which is based on the earlier works of Auer (1978), Ellefsen (1991) and Oke (2004). With this method, the land surfaces are divided into 17 types, and the measured temperature is standardized, which makes research in different areas more comparable.

In this study, we classified the urban surface of Zhengzhou City with the LCZ classification method and estimated the land surface temperature (LST). Based on the LCZ classification results and urban surface temperature, we calculated the urban heat island intensity and its distribution in Zhengzhou City in summer and winter. Finally, the temperature characteristics in different LCZs were analyzed.

\section{Research area and data}

\subsection{Research area}

Zhengzhou city is located in the central part of China, with a population of 10,120,000 within an urbanized area of about $550 \mathrm{~km}^{2}$. The area is in north temperate continental monsoon climatic region with an annual mean temperature of $15.6^{\circ} \mathrm{C}$ and an amount of yearly precipitation of $542 \mathrm{~mm}$. The average temperature in summer is $31.6^{\circ} \mathrm{C}$, and in winter is $7.8^{\circ} \mathrm{C}$. The study area, with a population of about 6 million, covers a $62 \mathrm{~km} \times 46 \mathrm{~km}$ rectangle in and around city center 
of Zhengzhou (Fig. 1). In recent years, due to rapid urbanization, urban surface varied a lot with a large area of built impervious surface and high-rise buildings.
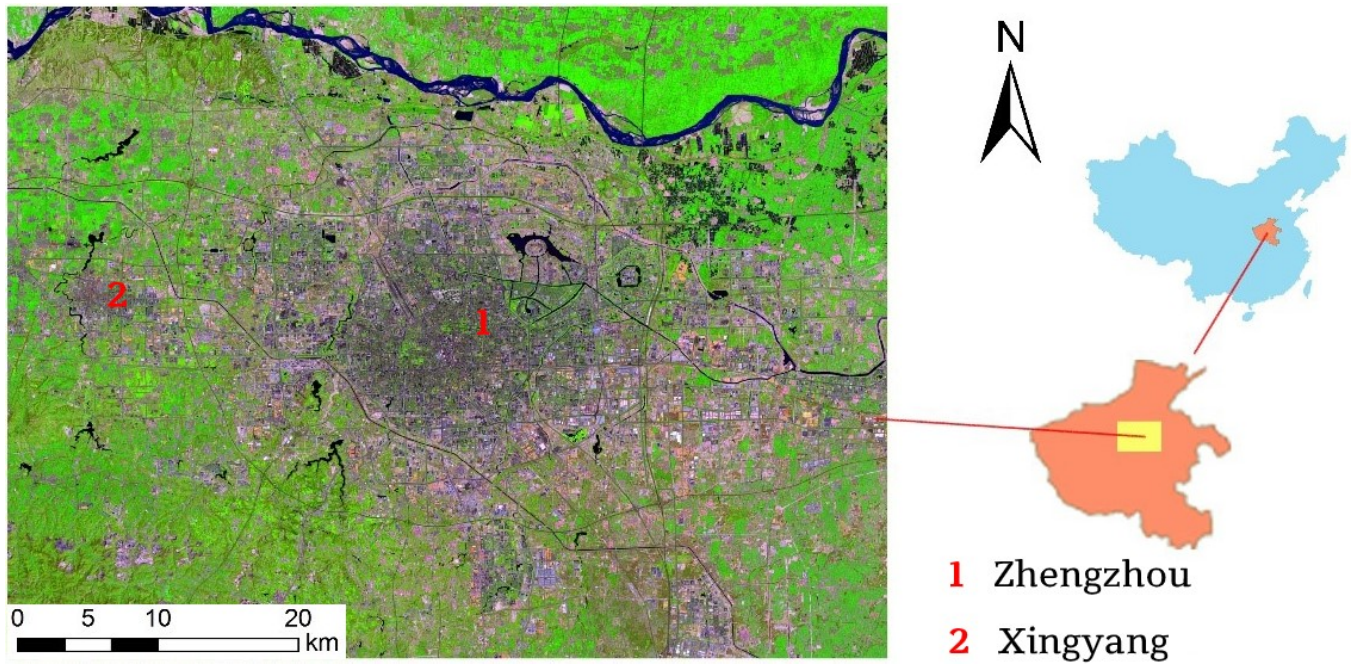

Fig. 1: Location of the research area.

\subsection{Data}

Landsat-8 data, Google map and Open Street Map (OSM) information were used in this study (Table 1). Landsat_8_OLI image (28 April 2017), with clear vegetation information, was selected for LCZ classification (Stewart \& Oke, 2012). Nevertheless, building-height information is not contained in the Landsat 8 image, as addition, OSM data and Google map information were added for LCZ classification. The LST were calculated with the Landsat_8_TIRS for two days, one in summer (28 July 2015) and one in winter (24 December 2017). We chose the summer image in 2015 as there was no suitable summer image of Zhengzhou City in 2017 and 2016 because of the extended cloud cover.

Table 1: Applied data sources.

\begin{tabular}{|c|c|c|c|c|}
\hline Function & Data & Date & Type & Resolution \\
\hline \multirow{2}{*}{ LCZ } & Landsat_8_OLI & 28 April 2017 & raster & $30 \mathrm{~m}$ \\
\cline { 2 - 5 } & OSM & 2017 & vector & - \\
\hline & Google map & 2017 & raster/vector & \\
\hline LST & Landsat_8_TIRS & 28 July 2015 & raster & $100 \mathrm{~m}$ \\
\hline & & 24 December 2017 & raster & $100 \mathrm{~m}$ \\
\hline
\end{tabular}

\section{Method}

\subsection{Calculation of urban surface factors}

According to the definition of LCZs (Stewart \& Oke, 2012) different LCZs are distinguished based on several surface cover properties. We can determine seven urban surface physical properties for dividing the research area into different climate zones. Because the method used in 
this study was different from Stewart \& Oke's, the physical properties characterizing the elements of the LCZ types are also different. Their calculation methods are as follows:

Building height $(B H)$ and building density $(B D)$ - The OSM database provides city building vector data including height information. The building vector map, acquired from OSM database in Zhengzhou, was overlapped with the latest remote sensing image to be spatially corrected and modified. And we also supplemented some missing buildings according to actual condition. The final urban building data covers almost all urban buildings in Zhengzhou. Building height and building density, with the resolution of $30 \mathrm{~m}$, were both calculated with the resample tool in ArcGIS. $B H$ values refer to the average building height in one $30 \mathrm{~m}$ pixel, and $B D$ values refer to the ratio of the built-up area to the total area also in one pixel.

Impervious surface fraction (ISF) and Bare soil index (BI) - The ISF was calculated with the spectral-unmixing method based on the "V-I-S" (Vegetation-Impervious Surface-Soil) model in ENVI 5.2 software. The calculation method of $B I$ was included in the calculation process of ISF.

Normalized difference vegetation index (NDVI) and Fraction of vegetation cover $(F V C)$ - both of them can reflect the distribution of vegetation. Based on the study on Fuzhou city (Lin \& Xu, 2017 ), the $F V C$ can be used to distinguish areas with different vegetation cover. These two values can be calculated as follows:

$$
\begin{gathered}
N D V I=\left(B_{N I R}-B_{R}\right) /\left(B_{N I R}+B_{R}\right) \\
F V C=\left(N D V I-N D V I_{\text {soil }}\right) /\left(N D V I_{\text {veg }}-N D V I_{\text {soil }}\right)
\end{gathered}
$$

where $B_{N I R}$ is the fifth band in the Landsat_ 8 database and the $B_{R}$ is the fourth band.

Modified normalized difference water index (MNDWI) - This index can be used to distinguish the water and the non-water areas. The values were calculated with a modified method $(\mathrm{Xu}$, 2005):

$$
\left.M N D W I=\left(B_{\text {Green }}-B_{M I R}\right) / B_{\text {Green }}+B_{M I R}\right)
$$

where $B_{\text {Green }}$ is pixel values from the green band, and $B_{M I R}$ is pixel values from the short-wave infrared band.

\subsection{Classification of $L C Z s$}

Local climate zones were classified with decision-tree method, which is one kind of supervised classification methods in ENVI software ( $\mathrm{Li} \& \mathrm{Yu}, 2007)$. According to the climate zone samples selected in Google map image, the range of the values for each surface cover properties in different LCZs (Table 2) was determined. The final LCZ decision tree is shown on Fig. 2. 
Gou Yuchen: The influence of urban scale spatial morphology on thermal environment in Zhengzhou, China - a case study

Table 2: Built and land cover LCZ types (Stewart \& Oke, 2012).

\begin{tabular}{|c|c|}
\hline Built types & Land Cover types \\
\hline LCZ-1 Compact high-rise & LCZ-A Dense trees \\
\hline LCZ-2 Compact midrise & LCZ-B Scattered trees \\
\hline LCZ-3 Compact low-rise & LCZ-C Bush, scrub \\
\hline LCZ-4 Open high-rise & LCZ-D Low plants \\
\hline LCZ-5 Open midrise & LCZ-E Bare rock / paved \\
\hline LCZ-6 Open low-rise & LCZ-F Bare soil / sand \\
\hline LCZ-7 Lightweight low-rise & LCZ-G Water \\
\hline LCZ-8 Large low-rise & \\
\hline LCZ-9 Sparsely built & \\
\hline LCZ-10 Heavy industry & \\
\hline
\end{tabular}

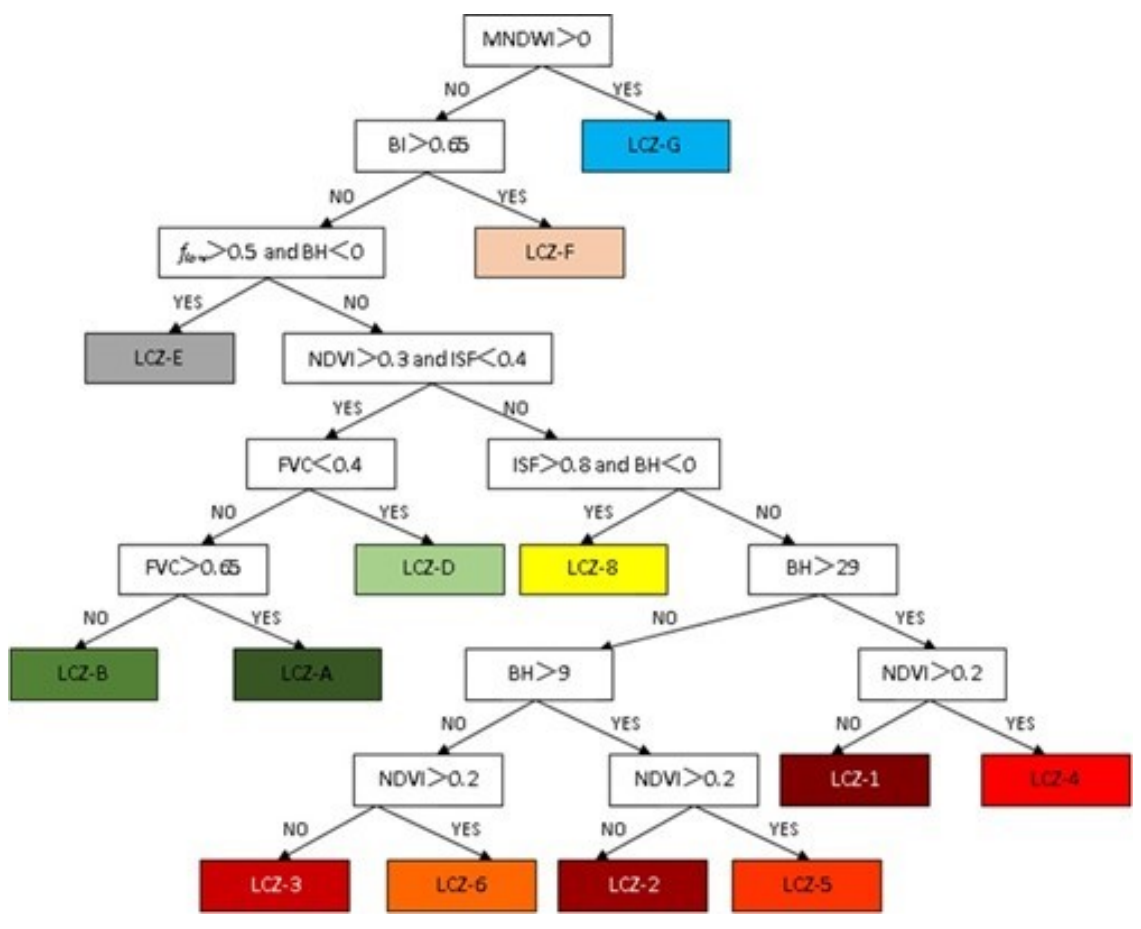

Fig. 2: Decision tree of LCZ classification.

\subsection{Estimation of urban surface temperature}

The surface temperature estimation process was performed on Landsat 8_TIRS data in ENVI using the radiation transfer equation by calculating the land surface emissivity. Since there have been many studies on the calculation of surface temperature applying radiation transfer equation (e.g. Anandababu et al., 2018; Rajeshwari \& Mani, 2014), the specific processes and equations will not be detailed here. 


\section{Results}

\subsection{LCZ classification}

As shown in Fig. 3, according to the actual situation in Zhengzhou City, 13 types of LCZs were finally classified. 7 of them are built types: LCZ-1, LCZ-2, LCZ-3, LCZ-4, LCZ-5, LCZ-6 and LCZ-8; and 6 kinds of land cover type: LCZ-A, LCZ-B, LCZ-D, LCZ-E, LCZ-F and LCZ-G. In order to analyze the distribution of LCZs in different regions, the research area was divided into built-up region and rural region.

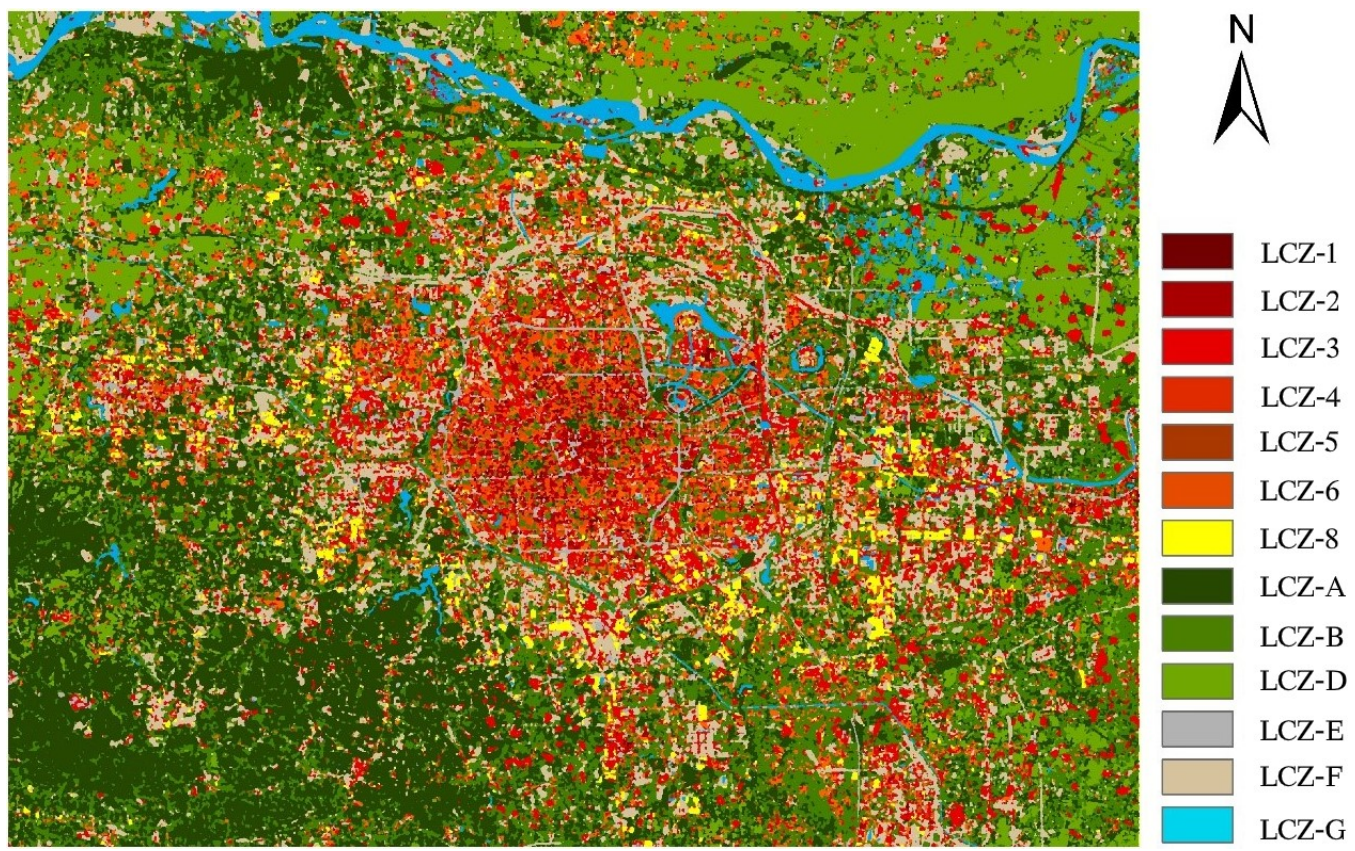

Fig. 3: Distribution of LCZ types occurring in the Zhengzhou research area.

Fig. 4. shows some statistical data about the extension of different LCZs relating to the total research area and distinguishing built and rural area. Some details:

Built types - The total area of the built types is $635.07 \mathrm{~km}^{2}$ that is $21.82 \%$ of the whole research area. High-rise types (LCZ-1 and LCZ-4) and mid-rises types (LCZ-2 and LCZ-5) are distributed mainly in the downtown of Zhengzhou City and in Xingyang County, as well as in the surrounding area of the airport in the southeast of the city. Low-rise types (LCZ-3 and LCZ-6) are located mainly in the rural region. LCZ-8 can be found around the built area.

Land cover types - The total area of the land cover types is $2275.33 \mathrm{~km}^{2}(78.18 \%$ of the whole research area). The dense and scattered trees (LCZ-A and LCZ-B) occupy large areas $\left(675.01 \mathrm{~km}^{2}(23.19 \%)\right.$ and $714.96 \mathrm{~km}^{2}(24.57 \%)$, respectively) locating in the mountains and gullies in the southwest and northwest of Zhengzhou. There is little vegetation in the city center, typically only some scattered trees in the city parks. LCZ-D contains mainly farms surrounding the city. There are large bare soils and sandy areas in the built areas, which may be related to urban construction works. 


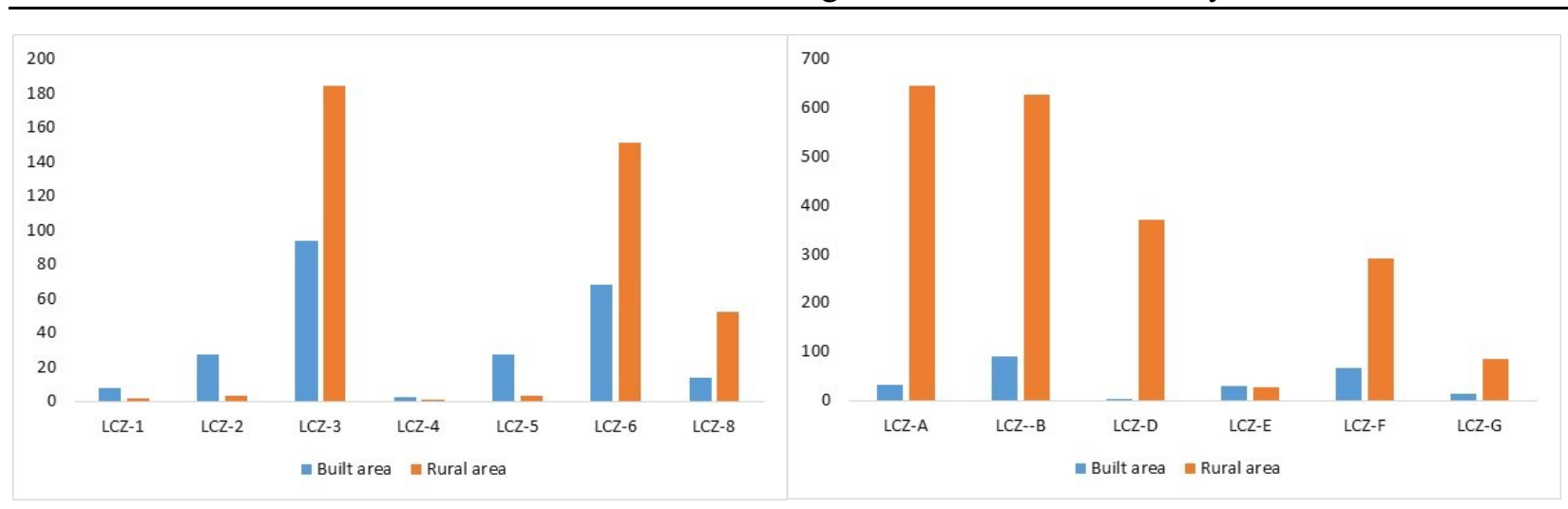

Fig. 4: Extension of LCZs $\left(\mathrm{km}^{2}\right)$ in different areas.

\subsection{Urban heat island}

According to the radiation transfer equation, we got the LST in summer and winter (Fig. 5). In summer, the maximum temperature is $56.8^{\circ} \mathrm{C}$ and the minimum temperature is $19.8^{\circ} \mathrm{C}$. In winter, the maximum temperature is $18.1^{\circ} \mathrm{C}$ and the minimum temperature is $-6.5^{\circ} \mathrm{C}$. We can see significant urban heat island effect in summer and urban cool island effect in winter.
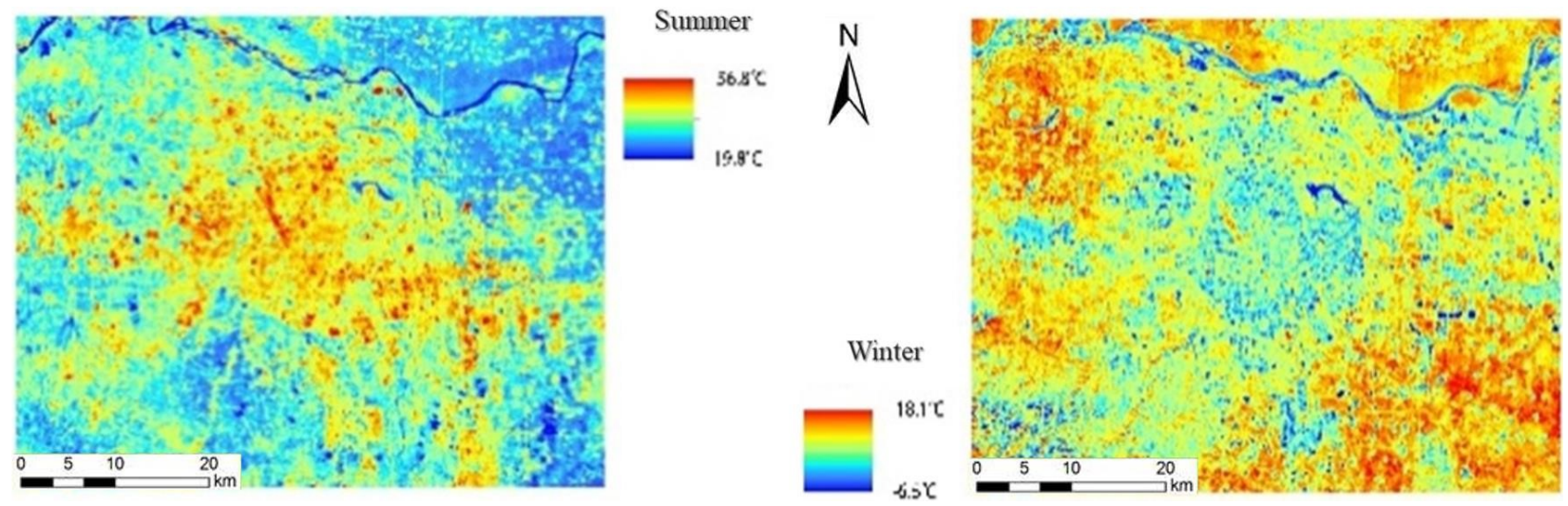

Fig. 5: Urban surface temperature distribution in summer (left) and in winter (right).

\subsubsection{Surface urban heat island intensity (SUHII)}

Traditionally, the detection of SUHII is conducted at two fixed in-situ stations, one in urban and the other in rural regions (e.g. Unger, 1996; Yang et al., 2013; Earl et al., 2016). However, usually, the definition of urban and rural areas is discrepant in different studies, which causes some confusion. If the calculation of the heat island intensity is based on the LCZ, the problem of blurry definition will be solved. In this study, based on the LCZ classification results, the average temperature in LCZ-3 and LCZ-A were calculated as the representation of urban area and rural area, respectively. As another approach, buffers with different widths (2, 4, 6 and $8 \mathrm{~km})$ were determined surrounding the built area, then the average temperatures in built areas and buffers were calculated in order to represent urban and rural areas. As Table 3. shows, the heat island intensity in summer was more intense: the LCZ-based intensity was $6.03{ }^{\circ} \mathrm{C}$, and the buffer-based values were all higher than $2.5^{\circ} \mathrm{C}$. In winter, an urban cool island effect existed in the urban area: 
the intensity based on LCZs was $-1.32{ }^{\circ} \mathrm{C}$, as for the buffer-based values they were all smaller than $-0.85^{\circ} \mathrm{C}$.

Table 3: Calculation results of surface urban heat island intensity.

\begin{tabular}{|c|c|c|c|}
\hline \multirow{2}{*}{\multicolumn{2}{|c|}{$\begin{array}{c}\text { SUHII } \\
\text { approach }\end{array}$}} & Summer & Winter \\
\hline & & \multicolumn{2}{|c|}{ Intensity $\left({ }^{\circ} \mathrm{C}\right)$} \\
\hline \multicolumn{2}{|c|}{ LCZ } & 6.03 & -1.32 \\
\hline \multirow{4}{*}{ buffer } & $2 \mathrm{~km}$ & 2.57 & -0.92 \\
\hline & $4 \mathrm{~km}$ & 3.01 & -0.86 \\
\hline & $6 \mathrm{~km}$ & 3.24 & -0.85 \\
\hline & $8 \mathrm{~km}$ & 3.46 & -0.86 \\
\hline
\end{tabular}

\subsubsection{Urban heat island patterns}

In order to describe the areal distribution of heat island, the normalized difference intensity of surface urban heat island (NDISUHI) was calculated with the following equation:

$$
N D I S U H I=\left(T_{i}-T_{\min }\right) /\left(T_{\max }-T_{\min }\right)
$$

Then the obtained values were divided into 5 levels with the standard deviation classification in ArcGIS. As Fig. 6. shows, in summer the area of the intensive heat island concentrated in the city center and in the southeast region of Zhengzhou, which is a new airport economic area. On the contrary, the situation was opposite in winter, as the city center was cooler than the rural area. The urban cool island effect in winter was as significant as the heat island effect in summer.
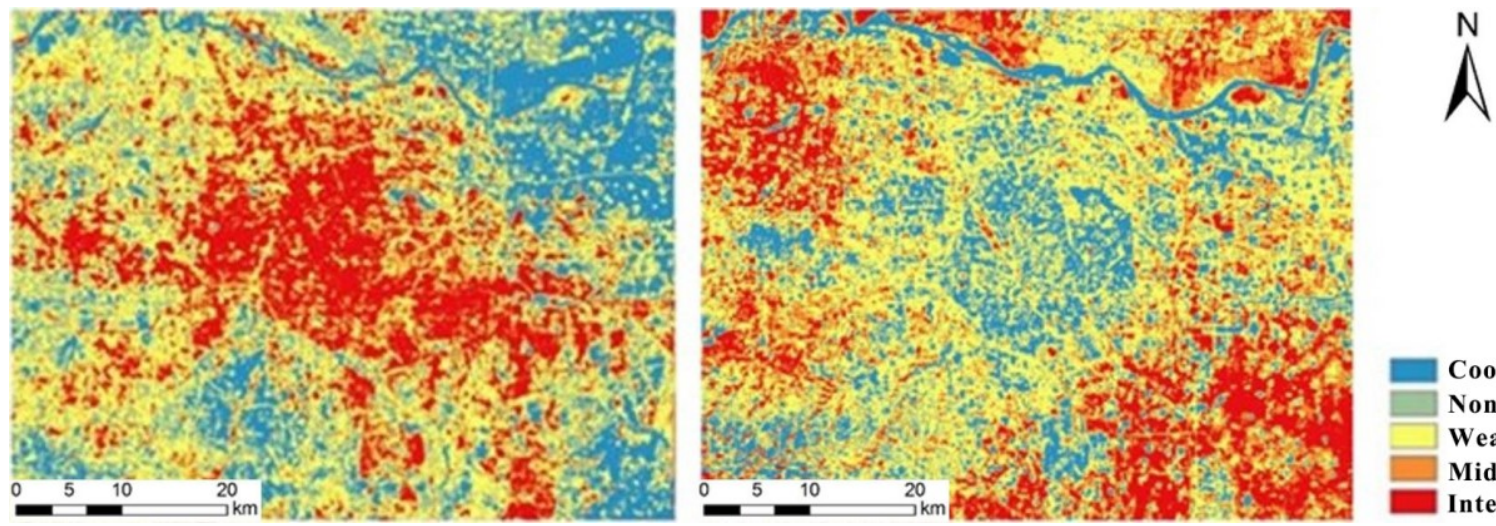

Fig. 6: Patterns of NDISUHI in summer (left) and in winter (right).

\subsection{Comparison of thermal characteristics among $L C Z s$}

Finally, the LCZ map and the LST map were overlapped to analyze the urban thermal environment in different LCZs. As Fig. 7. shows, in summer the average temperature in the built type areas $\left(39.3{ }^{\circ} \mathrm{C}\right)$ was higher than the one in the land cover type areas $\left(35.7^{\circ} \mathrm{C}\right)$. The average temperature in the densely built areas (LCZ-1, LCZ-2 and LCZ-3) was higher than in the open built areas (LCZ-4, LCZ-5 and LCZ-6). It could be seen that the surface temperature was lower in LCZs with more vegetation. But, the situation was opposite in winter, as of the temperature in 
the built type areas $\left(9.4^{\circ} \mathrm{C}\right)$ was lower than the one in the land cover type areas $\left(10.4^{\circ} \mathrm{C}\right)$. The average temperature in the densely built area (LCZ-1, LCZ-2 and LCZ-3) was also lower than in the open built areas (LCZ-4, LCZ-5 and LCZ-6). As for the effect of high-rise buildings on the surface temperature, the result is absolutely unclear.

In summer, the order of the zones based on thermal reaction is as follows: mid-rise area $\left(40.8{ }^{\circ} \mathrm{C}\right)>$ high-rise area $\left(39.3^{\circ} \mathrm{C}\right)>$ low-rise area $\left(38.9^{\circ} \mathrm{C}\right)$, while in winter, the order is the next: low-rise area $\left(9.6^{\circ} \mathrm{C}\right)>$ mid-rise area $\left(9.0^{\circ} \mathrm{C}\right)>$ high-rise area $\left(8.2^{\circ} \mathrm{C}\right)$.
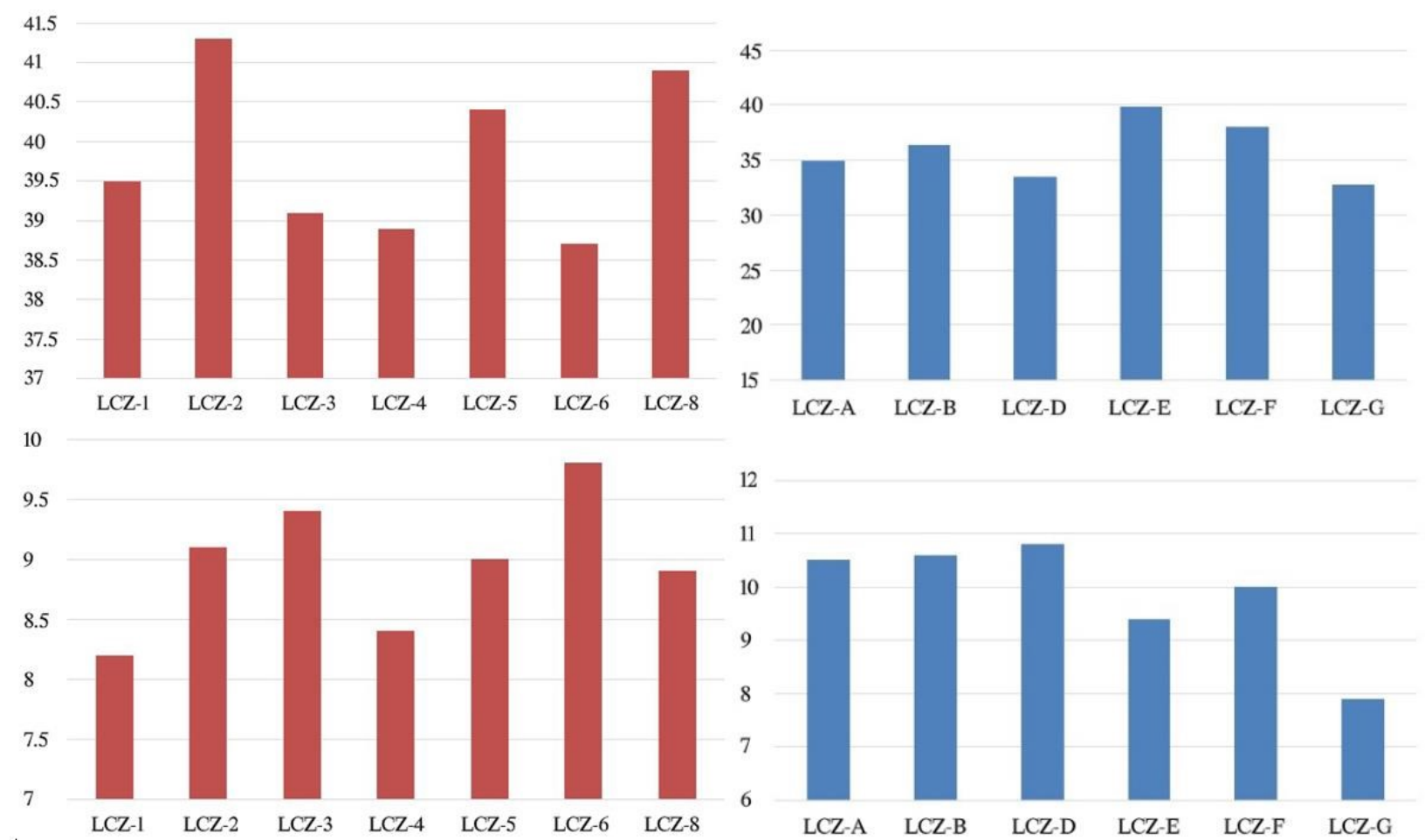

Fig. 7: Average temperatures $\left({ }^{\circ} \mathrm{C}\right)$ in different LCZs in summer (top) and in winter (bottom).

\section{Conclusions}

In this study, we determined the areas of those LCZ types in Zhengzhou (China) which are representative for the areas in and around the city using decision tree method based on seven geometric and surface cover properties. As a result, 13 LCZ types, including 7 built types and 6 land cover types were distinguished in the research area. We found that there were lots of areas with compactly built and few vegetation in central districts of Zhengzhou. Due to the urban construction works, the area of bare soil in the city area was also large.

In order to analyze the urban surface thermal environment, we calculated the surface urban heat island intensity in Zhengzhou based on LCZ classification and buffer approaches. In summer the heat island effect was strong with $6.03{ }^{\circ} \mathrm{C}$ of SUHII based on LCZ approach, but the cold island effect appeared in winter $\left(-1.32^{\circ} \mathrm{C}\right)$. By buffer, we calculated the SUHII again. The results show that the value of SUHII was higher than $2.5^{\circ} \mathrm{C}$ in summer and lower than $-0.8^{\circ} \mathrm{C}$ in winter. Comparing the LSTs in different LCZ, we found that the vegetation has a cooling effect in summer, but it has an opposite effect in winter as the vegetated areas were warmer at that time. 
The decision tree method proved to be feasible for LCZ classification, although it differs from Stewart and Oke's (2012) method. This study is just the beginning of LCZ research in Zhengzhou, in the near future the database used for LCZs and LSTs needs to be expanded in order to improve the accuracy of LCZ classification and to get more general (e.g. seasonal) results on LSTs.

\section{Acknowledgement}

The final form of this study complemented in the frame during the $\mathrm{PhD}$ study supported by Stipendium Hungaricum.

\section{References}

Anandababu, D., Purushothaman, B., M.,Suresh, B.S., 2018: Estimation of Land Surface Temperature using LANDSAT 8 Data. Int. J. Adv. Res. Idea. Innova. in Techno., 4: 177-186. Auer, A.H., 1978: Correlation of land use and cover with meteorological anomalies. J. Appl. Meteorol., 17: 636-643. https://doi.org/10.1175/1520-0450(1978)017<0636:COLUAC $>2.0 . \mathrm{CO} ; 2$

Earl, N., Simmonds, I., Tapper, N., 2016: Weekly cycles in peak time temperatures and urban heat island intensity. Environ. Res. Lett., 11: 074003. https://doi.org/10.1088/1748$\underline{9326 / 11 / 7 / 074003}$

Ellefsen, R., 1991: Mapping and measuring buildings in the canopy boundary layer in ten US cities. Energy Build., 15-16: 1025-1049. https://doi.org/10.1016/0378-7788(91)90097-M

$\mathrm{Li}, \mathrm{H}$., Yu, M., 2007: Wetland information extraction based on decision tree model. J. Geoinformation Sci., 9: 60-64\&73.

Lin, Z.L., Xu, H.Q., 2017: A study of urban heat island intensity based on "local climate zones". J. Geo-information Sci., 19: 713-722. https://doi.org/10.3724/SP.J.1047.2017.00713

Oke, T.R., 2004: Initial guidance to obtain representative meteorological observation sites. Geneva, WMO/TD No. 1250, 47 p.

Rajeshwari, A., Mani, N.D., 2014: Estimation of LST of Dindigul district using Landsat 8 data. Int. J. of Res. in Eni. Tech., 3: 122-126. https://doi.org/10.15623/ijret.2014.0305025

Stewart, I.D., 2011: A systematic review and scientific critique of methodology in modern urban heat island literature. Int. J. Climatol., 31: 200-217. https://doi.org/10.1002/joc.2141

Stewart, I.D., Oke, T.R., 2012: Local Climate Zones for urban temperature studies. Bull. Am. Meteorol. Soc., 93: 1879-1900. https://doi.org/10.1175/BAMS-D-11-00019.1

Unger, J., 1996: Heat island intensity with different meteorological conditions in a medium-sized town: Szeged, Hungary. Theor. Appl. Climatol., 54: 147-151. https://doi.org/10.1007/BF00865157

$X u, H . Q ., 2005:$ A study on information extraction of water body with the modified normalized Difference water index (MNDWI), J. Rem. Sens., 9: 589-595.

Yang, P., Ren, G., Liu, W., 2013: Spatial and temporal characteristics of Beijing urban heat island intensity. J. Appl. Meteorol. Climatol, 52: 1803-1816. https://doi.org/10.1175/JAMC-D-120125.1

Zhang, Q., Li, G.D., Wu, D.X., 2016: Relationship between urbanization and urban heat island effect in Zhengzhou. Urban Environ. Urban Ecol., 5: 1-6. 